ISSN:

\title{
EDUCAÇÃO AMBIENTAL À DISTÂNCIA: CAPACITAÇÃO EM DOCUMENTOS REFERÊNCIA
}

\author{
Berenice Gehlen Adams ${ }^{1}$, Marcelo Barcellos da Rosa², \\ Damaris Kirsch Pinheiro², Paulo Edelvar Corrêa Peres ${ }^{2}$ \\ ${ }^{1}$ Especialista em Educação Ambiental \\ ${ }^{2}$ Professores do Curso de Especialização em Educação Ambiental da UFSM
}

\section{RESUMO}

A presente pesquisa teve como principal objetivo buscar e desenvolver subsídios teóricos e práticos para o aprimoramento da Educação Ambiental (EA) através de um programa experimental de capacitação de EA à distância, para professores, pautado nos documentos referência que legitimam e fundamentam a EA: Lei № 9795/99, a Carta da Terra, e o Tratado de Educação Ambiental para Sociedades Sustentáveis e Responsabilidade Global. A metodologia utilizada foi a da pesquisa exploratória e aplicada através de realização de um programa de capacitação à distância, que iniciou em fevereiro de 2010, com 21 participantes de 9 estados brasileiros e terminou em 10 de maio completando 60 horas. As aulas foram realizadas por módulos que trataram das orientações para o ambiente virtual, do histórico da EA e de atividades de estudos com os documentos referência. Foram realizadas leituras, reflexões, exercícios dissertativos, e participação no fórum virtual. As tarefas promoveram associações dos documentos com práticas da EA. Contou com a participação de professores (13), técnicos (04) e especialistas (04), de nove estados brasileiros. Os resultados confirmaram que o programa promoveu maior segurança nas ações de EA. O programa possibilitou aos participantes ampliarem seus conhecimentos e suas experiências.

Palavras-chaves: Educação Ambiental, capacitação, Lei 9.795/99, Carta da Terra, tratado, sociedades sustentáveis, responsabilidade global

\section{ABSTRACT}

This research aims to develop theoretical and practical for the Enhancement of Environmental Education (EE) through an experimental program for training of EA at a distance, for teachers, based on the documents refer to legitimize and justify the EA: Law No. 9795/99, the Earth Charter and the Treaty on Environmental Education for Sustainable Societies and Global Responsibility. The methodology used was the exploratory research and applied by carrying out a program of distance training, which began in February 2010 with 21 participants from nine Brazilian states and ended on May 1 by completing 60 hours. Classes were held in the form of modules and addressed the guidelines for the virtual environment, the history of EA studies and activities with the reference documents. Readings were taken, reflections, exercises, essay, and participation in the virtual forum. The tasks promoted association of documents with practices of environmental education. With the participation of teachers (13), technical (04) and specialists (04), nine Brazilian states. The results showed that the program promoted greater safety in the actions of EA. The 


\section{Monografias Ambientais}

REMOA

ISSN:

program allowed participants to broaden their knowledge and experiences, which contributed to a better understanding of the construction process of EA. Furthermore, it allowed the recognition of reference of the EA documents as important teaching tools for the development of practical activities of EA, in line with its objectives and principles legitimate.

Key-words: Environmental Education, capacitation, teachers, Law number 9.795/99, "Carta da Terra“ (Earth letter), agreement, sustainable societies, global responsibility.

\section{INTRODUÇÃO}

Os problemas ambientais apontam o enorme descaso das atividades culturais para com o meio ambiente. Estes problemas, advindos das mais diferentes áreas da produção humana, precisam uma especial atenção por parte de entidades educadoras para que possam promover uma educação que possibilite a construção de uma sociedade sustentável.

Por isto, buscou-se, com esta pesquisa, experimentar um programa de capacitação que possibilitasse aos professores - e a outros profissionais ligados à Educação Ambiental (EA) conhecimento e experiências com os principais documentos referência da EA que são: a Lei № 9795/99 (BRASIL, 1999), a Carta da Terra (1992) e o Tratado de Educação Ambiental para Sociedades Sustentáveis e Responsabilidade Global (FÓRUM INTERNACIONAL DAS ONG's, 1992).

É necessário que se compreenda como foi o processo de construção da EA por diferentes coletivos e como esta se tornou uma prática legítima e interdisciplinar, possibilitando melhorar a qualidade da aplicação da EA.

Entre muitos outros documentos importantes que fundamentam a EA, estes foram selecionados, pois: o primeiro legitima a EA no Brasil; o segundo, foi elaborado em importante Fórum, com a participação de diversas Organizações Não Governamentais (ONG's) e fundamenta o Programa Nacional de Formação de Educadores Ambientais (ProFEA), do Ministério do Meio Ambiente (MMA); e o último, é um documento que envolve a sociedade civil mundial, que também surgiu de evento paralelo à Conferência das Nações Unidas sobre Meio Ambiente e Desenvolvimento (Eco 92), o Fórum das ONG's, agrupando ideias de pessoas e de diferentes grupos de mais de 120 países.

O programa de capacitação voltado para professores e profissionais da EA se justifica pelas evidências de que estes não utilizam os documentos referência da EA para balizarem suas atividades pedagógicas. Isto implica na não compreensão dos objetivos e dos princípios da EA que foram elaborados por diferentes coletivos e que fundamentam essa prática educacional.

Veiga et all (2005), salientam que

[...] no Brasil, a cobertura dos $\mathrm{PR}^{1}$ cresceu significativamente de $40 \%$ em 2001 para 58,4\% em 2004 (com taxa de crescimento de $45 \%$ ). A cobertura das $D^{2}{ }^{2}$ é baixa para os dois anos (3,2\% em 2001 e $4,5 \%$ em 2004). A cobertura da modalidade ITAD ${ }^{3}$ reduziu-se de $76,7 \%$ para 65,8\% entre 2001 e 2004 (VEIGA, 2005, pp. 15-16).

\footnotetext{
${ }^{1}$ PR - Projetos

${ }^{2}$ DE - Disciplinas Especiais

${ }^{3}$ ITAD - Inserção da Temática Ambiental na Disciplina
} 


\section{Monografias Ambientais}

REMOA

ISSN:

Compreende-se, portanto, que um programa de capacitação de EA à distância poderá colaborar para uma melhor compreensão sobre as modalidades da EA promovendo práticas alinhadas aos seus princípios e às suas finalidades.

A EA desponta no cenário educacional e social como alternativa para a inversão das posturas cada vez mais degradantes que se acentuaram em meados do século passado e tornouse legítima com a implantação da Lei № 9.795/99, que instituiu a Política Nacional de Educação Ambiental no Brasil (PNEA).

Conforme Quintas (2004),

A Educação Ambiental, para cumprir a sua finalidade, conforme definida na Constituição Federal, na Lei 9.795/99, que institui a Política Nacional de Educação Ambiental e em seu Decreto regulamentador $(4.281 / 02)$, deve proporcionar as condições para o desenvolvimento das capacidades necessárias; para que grupos sociais, em diferentes contextos socioambientais do país, exerçam o controle social da gestão ambiental pública (QUINTAS, 2004, p. 127).

Sabe-se que ainda predomina, na sociedade, a visão antropocêntrica de que ambiente é o que está fora das pessoas, como se estas não fossem parte integrante deste meio e sim, usuários de seus recursos.

\begin{tabular}{|l|l|}
\hline $\begin{array}{l}\text { Formação humana e técnica } \\
\text { clássica }\end{array}$ & $\begin{array}{l}\text { Profissional alfabetizado } \\
\text { ecologicamente }\end{array}$ \\
\hline $\begin{array}{l}\text { Autoridade: autoritário(a); } \\
\text { antropocêntrico(a) }\end{array}$ & $\begin{array}{l}\text { Humildade: dialoga com o mundo em } \\
\text { condições de igualdade }\end{array}$ \\
\hline $\begin{array}{l}\text { Trabalha principalmente com o } \\
\text { que sabe }\end{array}$ & $\begin{array}{l}\text { Trabalha com o saber do(a) outro(a) e } \\
\text { o } \\
\text { que não sabe }\end{array}$ \\
\hline Razão (lado esquerdo do cérebro) & $\begin{array}{l}\text { Intuição, emoção (lado direito do } \\
\text { cérebro) } \\
\text { equilibrada com razão }\end{array}$ \\
\hline O(a) outro(a) entra no meu mundo & $\begin{array}{l}\text { Eu compartilho o mundo com o(a) } \\
\text { outro(a) }\end{array}$ \\
\hline $\begin{array}{l}\text { Fechado(a) em si e no seu próprio } \\
\text { mundo }\end{array}$ & Eu faço parte de um todo maior \\
\hline $\begin{array}{l}\text { Predomina a expiração(eu sei >o } \\
\text { outro não sabe) }\end{array}$ & $\begin{array}{l}\text { Expiração e inspiração equilibrados } \\
\text { (sabemos e não sabemos) }\end{array}$ \\
\hline Eu decido / Eu / Ego-ação & Nós decidimos / Equipe / Eco-ação \\
\hline Hierarquia & Horizontalidade, policentrismo, redes \\
\hline Disciplina: fragmentação & Interdisciplinaridade: holos \\
\hline
\end{tabular}

Fonte: Munhoz, 2004, p. 151.

\section{Quadro 1 - Formação humana e técnica}

Da mesma forma que uma educação centrada na técnica promove a visão antropocêntrica, os processos de ensino que constituem os programas de formação de professores também interferem diretamente para a perpetuação de processos educacionais que privilegiam a disciplina (fragmentação do saber), o cognitivo (centrado na memorização), a competição (por melhores 
ISSN:

notas, preparação para vestibular). Este tipo de formação, recebida pelos professores, acaba direcionando a EA para disciplinas ligadas às Ciências Naturais.

O fato mencionado de que professores trabalhem a educação ambiental preferencialmente com o viés ecológico, pode advir de dois fatores: o primeiro [...] diz respeito à questão da formação do professor, uma vez que esta se desenvolve, no contexto atual, com um forte componente fragmentador, o que direciona uma prática também fragmentada, gerando a não valorização da educação como processo integral; o segundo, um resquício histórico, para o qual a questão da educação ambiental se configura com o mesmo tratamento dado pelos movimentos ambientalistas - de forma puramente preservacionista (GOUVÊA, 2006, p. 169).

Em levantamento feito por Fracalanza et all (2008), sobre a Educação Ambiental no panorama da produção acadêmica, este destaca que:

[...] A realização de práticas de Educação Ambiental, no âmbito da educação escolarizada, entre outros aspectos, depende de uma adequada formação de profissionais para o magistério. E, deve-se convir, face à diversidade de propostas de Educação Ambiental, a formação adequada do professor necessita, também, de acesso às informações disponíveis e sistematizadas pela produção acadêmica e científica (FRACALANZA et all, 2008, p.4).

A EA, portanto, tem diferentes abordagens e uma ampla gama de interpretações. Medina compreende que "a EA é um campo de conhecimento em formação, permeado por contradições e com um histórico que lamentavelmente torna mais complexo o seu processo de assimilação" (MEDINA, 2001, p.17).

Trajber e Mendonça (2006), organizadoras de um projeto de pesquisa - realizado em âmbito nacional - buscaram reconhecer "O que fazem as escolas que dizem que fazem Educação Ambiental?".

É interessante constatar que os pesquisadores encontraram escolas em que os respondentes tinham dificuldades em definir a Educação Ambiental ou afirmar com convicção que esta existia ou não na instituição. Associado a isto, foi possível identificar casos em que os respondentes não mencionaram projetos e atividades que poderíamos classificar como sendo de Educação Ambiental (segundo princípios básicos contidos na Política Nacional de Educação e no Programa Nacional de Educação Ambiental, por exemplo), por não as considerarem como tal (TRAJBER e MENDONÇA, 2006, p. 76).

Se esta dificuldade de compreensão da EA foi reconhecida na pesquisa realizada, imaginase que há, também, a falta de compreensão da EA como um processo educacional interdisciplinar. O conceito "interdisciplinaridade" é um conceito chave para que se possa compreender a EA como processo permanente a ser inserido nas propostas educacionais. "A interdisciplinaridade tem sido definida como uma estratégia que busca a união de diferentes disciplinas para tratar um problema comum" (LEFF, 2000, p.33).

Conforme Coimbra (2000), o termo

interdisciplinar consiste num tema, objeto ou abordagem em que duas ou mais disciplinas intencionalmente estabelecem nexos e vínculos entre si para alcançar um conhecimento mais abrangente, ao mesmo tempo diversificado e unificado [...] Cada disciplina, ciência ou técnica mantém a sua própria identidade [...] É essencial na interdisciplinaridade que a 


\section{Monografias Ambientais}

ISSN:

ciência e o cientista continuem a ser o que são, porém intercambiando hipóteses, elaborações e conclusões (COIMBRA, 2000, p. 58).

Pode-se compreender que a interdisciplinaridade não nega as disciplinas, pelo contrário, valoriza-as, porque quando se juntam algumas para analisar e/ou equacionar problemas, conseguem-se melhores resultados, que quando analisados por disciplinas isoladas. "Nos dias de hoje, é sabido que o acervo e o formato científico-tecnológico montado apenas em bases disciplinares perdem sua força quando se trata de equacionar problemas" [...] (PHILIPPI, 2000, p.4). Portanto, para se compreender a EA é preciso, fundamentalmente, compreender a interdisciplinaridade e

[...] é preciso entender que a interdisciplinaridade é muito mais um ponto de partida do que um ponto de chegada, e que ela não é dada de antemão, através de fórmulas ou regras, mas se constrói, em um processo criativo, a múltiplas mãos, necessitando para isso de um tempo e de uma dinâmica de trabalho bastante distintos de um processo de pesquisa disciplinar (ZANONI, 2000, p. 118).

A Educação à Distância (EAD) vem evoluindo, cada vez mais, pelos avanços tecnológicos e principalmente pela popularização da Internet. Este tipo de educação requer um ambiente virtual de aprendizagem, que tem suas vantagens e desvantagens.

Entre as vantagens, destaca-se: o rompimento de barreiras físicas - possibilitando realização de cursos que, de forma presencial, seria impossível devido à distância geográfica -; e a flexibilidade de horários para realização das aulas, o que não acontece em cursos presenciais. Por outro lado, como desvantagem, salienta-se: a dependência de recursos tecnológicos; dependência de redes de transmissão de dados estáveis; a necessidade de equipamentos modernos e atualizados; e no processo ensino/aprendizagem, conforme aponta Santos (2006), "o distanciamento físico professor/aluno, impõe limitações na construção de valores agregados ao processo educativo presencial no que toca a aplicação dos métodos de avaliação disponíveis" (SANTOS, s/p, 2006).

Ao contrário do que muitos compreendem por EAD como um sistema de aprendizagem mecanizado, conforme Coelho e Fialho (2007), este pode ser

[...] inspirado nas Teorias Construtivistas/Construcionistas [e] deve permitir ao estudante o máximo de interação, respeitando, ainda, as representações virtuais que pode estabelecer, ou seja, esquemas de assimilação, se falamos de Piaget, ou zonas de desenvolvimento, se nos suportamos em Vygotsky. Estudantes não devem, apenas, tomar decisões, mas, sobretudo, participar, experimentar e experienciar o conhecimento (COELHO, FIALHO, p 166, 2007).

Para Belloni (2002), a prática da EAD necessita de reflexões sobre o uso das atuais tecnologias de informação e comunicação no campo da educação e sobre [...].

Embora apresente várias desvantagens em relação a programas educacionais presenciais, a EAD se configura em uma ferramenta importantíssima na área educacional e pode ser utilizada para suprir lacunas referentes a processos permanentes de capacitação de professores.

A principal questão a ser respondida, neste trabalho, a partir de uma pesquisa exploratória e estudo de caso é: "A qualidade da prática da EA pode ser melhorada através de um programa de Educação Ambiental à Distância para Capacitação em Documentos Referência?"

O objetivo da pesquisa foi o de buscar e desenvolver subsídios teóricos e práticos para o aprimoramento da EA através de um programa experimental de capacitação à distância, para professores. 


\section{Monografias Ambientais}

ISSN:

Para alcançar este objetivo pretendeu-se:

- Captar professores e profissionais interessados na EA para receberem capacitação de EA com documentos referência em um programa experimental gratuito, desenvolvido à distância;

- capacitar professores e profissionais da EA para a compreensão dos princípios e das finalidades da EA apresentados nos principais documentos referência: a Lei № 9.795/99, a Carta da Terra e o Tratado de Educação Ambiental para Sociedades Sustentáveis e Responsabilidade Global, através de um programa de capacitação, desenvolvido em ambiente virtual para aprendizagem;

- realizar, a partir do ambiente virtual, atividades pedagógicas que promovam leituras, experiências e reflexões dos principais documentos referência de EA;

- incentivar ações pedagógicas de EA com base nos documentos referência;

- apresentar publicações governamentais e diferentes materiais pedagógicos relacionados à $E A$, através de diferentes recursos: textos, artigos, livros em arquivos, links para vídeos e sites relacionados à $E A$, apresentações em multimídia.

- apresentar e trocar sugestões de ações de EA entre os participantes do curso para que possam colaborar para a superação de dificuldades encontradas; e

- avaliar a relevância do programa de capacitação com os alunos.

\section{METODOLOGIA}

Para o desenvolvimento do programa foram realizadas as seguintes ativi-dades:

- Elaboração do plano de curso;

- estabelecimento de parceria entre o Projeto Apoema - Educação Ambiental e o Portal Virtual Amigos da Natureza, para o ambiente virtual de aprendizagem;

- criação do ambiente virtual de aprendizagem para o programa, cujo ende-reço é: www.amigosdanatureza.net/projetoapoema;

- pré-inscrições no portal virtual do Projeto Apoema - Educação Ambiental para os interessados, até atingir o número de 50 pré-inscritos (em dezembro de 2009 - em duas semanas já alcançou 50 pré-inscritos);

- abertura de inscrição para os pré-inscritos (janeiro de 2010);

- início do programa de capacitação com carga horária de 60h (fevereiro de 2010);

- questionários aplicados com os participantes do curso, antes e depois do programa (apurou-se o que os motivou para fazer a capacitação e o grau de importância desta proposta).

- término das aulas em 14 de abril de 2010; e

- entrega de todas as atividades e do formulário de avaliação do programa em 1으 de maio de 2010.

As aulas foram realizadas no ambiente virtual por módulos:

- Os dois módulos iniciais foram referentes à orientações para o ambiente virtual e histórico da EA.

- Os demais módulos relacionaram-se à estudos com os documentos, iniciando pela Lei, depois a Carta da Terra e, por último, o Tratado de EA.

- As atividades propostas foram realização de leituras, reflexões, exercícios dissertativos e participação no fórum. 


\section{Monografias Ambientais}

REMOA

ISSN:

- Os materiais didáticos foram textos, artigos, vídeos, para associações do documento em estudo ao material adicional selecionado e às atividades propostas como tarefas.

- As tarefas realizadas foram enviadas para a tutora que avaliava individualmente dúvidas e dificuldades apontadas, dando retorno tanto pelo fórum do ambiente virtual quanto por mensagem particular.

Os documentos foram apresentados, na íntegra, nas aulas desenvolvidas no ambiente virtual.

Inicialmente trabalhou-se em dois módulos: atividades referentes a orientações sobre o ambiente virtual e ao histórico da EA.

Em seguida, foram iniciados os módulos dos estudos com os documentos.

Cada aula abordou uma das partes dos documentos, iniciando pela Lei, depois a Carta da Terra e, por último, o Tratado.

Nas aulas foram propostas a realização de leituras e de atividades, ora de reflexão, ora de exercícios dissertativos para serem postados no fórum do ambiente de aprendizagem e foram utilizados textos, artigos, vídeos, para ampliarem as abordagens sempre fazendo associações do documento em estudo ao material adicional selecionado e às atividades propostas como tarefas.

As aulas trabalharam os documentos referência por etapas e para cada etapa foram feitas associações dos documentos referência com práticas pedagógicas que podem ser conhecidas, na íntegra, pelo caderno de atividades.

A realização das atividades promoveram reflexões, associações e vivências com os fundamentos dos documentos, possibilitando uma ampliação da percepção sobre estes como instrumentos pedagógicos, além de balizadores da EA.

As respostas de algumas atividades foram enviadas ao ambiente virtual para propor um intercâmbio entre diferentes ideias e experiências.

A avaliação do aprendizado ocorreu como processo contínuo, na medida em que as atividades eram realizadas. Algumas observações e esclarecimentos de dúvidas foram । das diretamente para o endereço eletrônico dos alunos, outras pelo fórum do ambiente virtua.

Foram utilizados dois questionários. Um foi aplicado no início do programa, para diagnosticar conhecimentos prévios e expectativas dos alunos quanto ao curso e outro no final para verificar se os objetivos foram alcançados.

\section{RESULTADOS E DISCUSSÃO}

Em início de dezembro de 2009, no ambiente virtual do Projeto Apoema - Educação Ambiental, foram abertas pré-inscrições para interessados em participar do programa de capacitação à distância.

Em duas semanas foram recebidas 50 pré-inscrições. Como a meta era alcançar 50 préinscritos, as pré-inscrições encerraram-se no dia 18 de dezembro de 2009.

Em janeiro de 2010, os pré-inscritos receberam, via e-mail, o plano do curso e a ficha de inscrição que deveria ser preenchida e entregue por e-mail ou por agência de correio, até o dia 15 de fevereiro de 2010.

Destes 50 pré-inscritos, 27 enviaram a ficha de inscrição em tempo, representando a participação de $57 \%$ dos interessados iniciais e destes 27 inscritos, somente 21 começaram a fazer o curso, representando $77 \%$ dos inscritos no programa. 
O período de virada de ano certamente inviabilizou a participação de alguns interessados, pois muitos estavam entrando em férias, ou mesmo usufruindo delas.

Foi uma preocupação inicial saber por que o participante desejou fazer a capacitação para conhecer o seu perfil a fim de compreender qual a fonte de motivação e o grau de interesse dos alunos pelo programa.

As respostas foram enviadas na ficha de inscrição e evidenciaram uma real preocupação pela compreensão da EA a partir de fundamentos legais e legítimos, como os documentos referência, além de uma preocupação para com o exercício da sua cidadania ambiental.

Tabela 2 - Contexto geográfico, atividade profissional, conclusão do programa e resultados

\begin{tabular}{|c|c|c|c|c|}
\hline Estado & Cidade & $\begin{array}{c}\text { Aluno } \\
\mathrm{s}\end{array}$ & Atividade & Concluiu \\
\hline Acre - AC & $X$ & 00 & $X$ & $x$ \\
\hline Alagoas - AL & $x$ & 00 & $x$ & $x$ \\
\hline Amapá - AP & $\mathrm{x}$ & 00 & $\mathrm{X}$ & $x$ \\
\hline Amazonas - AM & $x$ & 00 & $x$ & $x$ \\
\hline Bahia - BA & $\begin{array}{c}\text { Livramento de Nossa } \\
\text { Senhora }\end{array}$ & 01 & Professora & Sim \\
\hline Ceará - CE & $\mathrm{X}$ & 00 & $x$ & $x$ \\
\hline $\begin{array}{c}\text { Distrito Federal - } \\
\text { DF } \\
\end{array}$ & $x$ & 00 & $x$ & $x$ \\
\hline Espírito Santo - ES & $X$ & 00 & $X$ & $X$ \\
\hline Goiás-GO & Goiânia & 01 & Analista Microbiológico & Sim \\
\hline Maranhão - MA & Santa Luzia do Paruá & 01 & Professor & Sim \\
\hline Mato Grosso - MT & $\mathrm{X}$ & 00 & $\mathrm{x}$ & $\mathrm{x}$ \\
\hline $\begin{array}{l}\text { Mato Grosso do Sul } \\
- \text { MS }\end{array}$ & $x$ & 00 & $\mathrm{X}$ & $x$ \\
\hline Minas Gerais - MG & $\begin{array}{c}\text { Ouro Branco, } \\
\text { Tenente Portela, } \\
\text { Belo Horizonte e } \\
\text { Montes Claros }\end{array}$ & 04 & $\begin{array}{c}\text { Monitor Ambiental, } \\
\text { Educador Ambiental, } \\
\text { Professora e Consultora } \\
\text { de Qualidade }\end{array}$ & $\begin{array}{l}\text { Sim } \\
\text { Sim } \\
\text { Sim } \\
\text { Não }\end{array}$ \\
\hline Pará - PA & $\mathrm{X}$ & 00 & $\mathrm{X}$ & $\mathrm{x}$ \\
\hline Paraíba - PB & João Pessoa & 01 & Turismólogo & Sim \\
\hline Paraná - PR & $\begin{array}{l}\text { Santo Antônio do } \\
\text { Caiuá e Guarapuava }\end{array}$ & 02 & $\begin{array}{c}\text { Gestora Ambiental e } \\
\text { Professora }\end{array}$ & $\begin{array}{l}\text { Não } \\
\text { Sim }\end{array}$ \\
\hline Pernambuco - PE & $\mathrm{X}$ & 00 & $\mathrm{X}$ & $\mathrm{X}$ \\
\hline Piauí - PI & $\mathrm{X}$ & 00 & $x$ & $x$ \\
\hline Rio de Janeiro - RJ & $\begin{array}{c}\text { Rio de Janeiro e } \\
\text { Janguá }\end{array}$ & 02 & Teatróloga e Professora & $\begin{array}{l}\text { Sim } \\
\text { Não }\end{array}$ \\
\hline $\begin{array}{c}\text { Rio Grande do } \\
\text { Norte - RN }\end{array}$ & $x$ & 00 & $x$ & $\mathrm{x}$ \\
\hline $\begin{array}{l}\text { Rio Grande do Sul - } \\
\text { RS }\end{array}$ & $\begin{array}{l}\text { Xangri-lá e Porto } \\
\text { Alegre }\end{array}$ & 02 & $\begin{array}{c}\text { Professora e Técnico em } \\
\text { Monitoramento e } \\
\text { Controle Ambiental }\end{array}$ & $\begin{array}{l}\operatorname{Sim} \\
\operatorname{Sim}\end{array}$ \\
\hline Rondônia - RO & $x$ & 00 & $\mathrm{x}$ & $x$ \\
\hline
\end{tabular}


ISSN:

\begin{tabular}{|c|c|c|c|c|}
\hline Roraima - RR & $x$ & 00 & $x$ & $x$ \\
\hline Santa Catarina - SC & $\begin{array}{l}\text { Biguaçú e } \\
\text { Florianópolis }\end{array}$ & 02 & $\begin{array}{c}\text { Engenheiro Agrônomo e } \\
\text { Professora }\end{array}$ & $\begin{array}{l}\text { Não } \\
\text { Sim }\end{array}$ \\
\hline São Paulo - SP & $\begin{array}{l}\text { Sorocaba, Piacatu, } \\
\text { Severínia, São } \\
\text { Bernardo do Campo } \\
\text { e Diadema }\end{array}$ & 05 & $\begin{array}{c}\text { Bióloga, Secretária de } \\
\text { Gestão Ambiental, } \\
\text { Professora (3), }\end{array}$ & $\begin{array}{l}\text { Sim } \\
\text { Sim } \\
\text { Sim } \\
\text { Sim } \\
\text { Sim }\end{array}$ \\
\hline Sergipe - SE & $x$ & 00 & $X$ & $x$ \\
\hline Tocantins - TO & $x$ & 00 & $x$ & $x$ \\
\hline 9 Estados & $\begin{array}{l}21 \text { Cidades } / 6 \\
\text { Capitais }\end{array}$ & 21 & $\begin{array}{l}13 \text { Professores, } 04 \\
\text { Técnicos e } 04 \\
\text { Especialistas }\end{array}$ & 17 \\
\hline
\end{tabular}

As questões do questionário diagnóstico versaram sobre as relações e compreensões do participante quanto: ao conceito de EA; à experiência com EA; aos documentos referência da EA; à prática cidadã e responsável de EA (na comunidade ou empresa); ao conceito de meio ambiente, visão sobre problemas ambientais; e a bibliografia base de seu conhecimento prévio sobre EA. 66 \% dos alunos preencheram o formulário do questionário diagnóstico.

Dos 14 participantes que enviaram as respostas até o dia do levantamento dos dados, foi possível verificar o que segue:

- Do total, 12 participantes já trabalharam e/ou trabalham com EA, represen-tando 85\%.

Dos 14 respondentes constatou-se que

- 71\% conheceram a Carta da Terra e a Lei № 9.795/99 entre os anos de 2000 e 2009 enquanto que $29 \%$ dos alunos não conheciam estes documentos;

- 42\% dos participantes conheceram o Tratado de Educação Ambiental para Sociedades Sustentáveis e Responsabilidade Global entre 1992 e 2006, enquanto que 58\% não o conheciam.

\section{Gráfico 1 - Conhecimento dos documentos referência da EA}

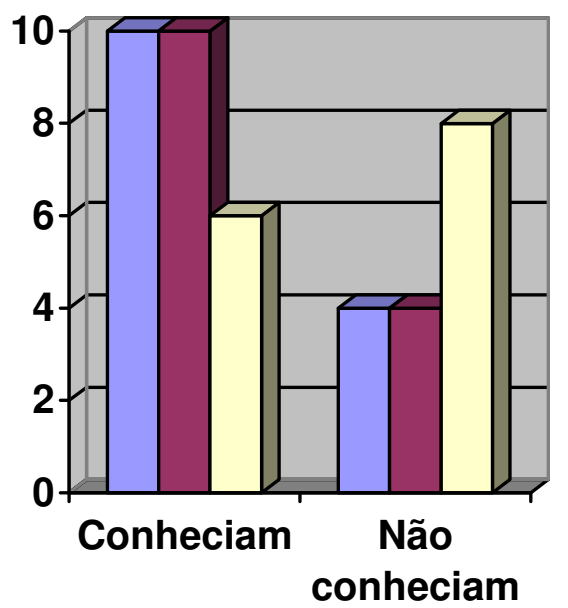

\begin{tabular}{|l|}
$\square$ Lei № 9.795/99 \\
$\square$ Carta da Terra \\
$\square$ Tratado de EA \\
\hline
\end{tabular}

O ambiente virtual foi construído especificamente para este programa. O ambiente do aluno, que se configurou como sendo a sala de aula virtual, contou com diversos recursos. Ao 


\section{Monografias Ambientais}

ISSN:

acessar o Painel do Aluno, através de um "login" e senha, os alunos tiveram acesso à sala de aula virtual, que se configurou em dois blocos. Um era correspondente ao bloco "menu", contendo listagem das opções: Aulas, Fórum, Glossário, Professor On-line, Midiateca, Meus Dados, Minha Senha e Sair do Painel. Já no bloco da direita estavam os "links" para acesso ao ambiente de aprendizagem representados por ícones, que levavam para os mesmos "links" que os itens do Menu, do bloco da esquerda.

O programa teve início no dia previsto (24 de fevereiro de 2010), com abertura do ambiente virtual, distribuição de senhas para os inscritos e orientações sobre o ambiente de aprendizagem e as ferramentas disponibilizadas para interati-vidade. Isto foi feito através de mensagem enviada para endereço postal eletrônico (e-mail) dos participantes.

$\mathrm{Na}$ medida em que se iniciaram as atividades, os alunos enviaram suas dúvidas e dificuldades, que foram esclarecidas.

Em poucos dias, todos os inscritos passaram a frequentar o ambiente virtual para efetivação das aulas on-line. Alguns tiveram problemas de acesso ao ambiente virtual de aprendizagem, tornando-se necessário criar nova senha de acesso.

As aulas foram sendo liberadas de acordo com o cronograma previsto no programa do curso, bem como os materiais de leitura e os links para apresentação dos documentos e para vídeos educativos.

Cada aula contou com duas tarefas a serem enviadas, por e-mail, para a professora, até uma data prevista.

Os estudos detalhados com os principais documentos da EA promoveram a compreensão de que cabe aos educadores, darem "eco" a estes "contratos éticos" que assumiram para com o Planeta, para com eles mesmos e colocar a EA em prática, diariamente.

No final do programa foi elaborado um questionário, a fim de verificar se as ferramentas virtuais e as atividades desenvolvidas foram relevantes como recurso para aprimorar práticas de EA.

Ao analisar as respostas obtidas no questionário aplicado pelo ambiente virtual pode-se considerar que os objetivos do programa foram alcançados, apesar de se perceber algumas lacunas referentes à promoção de interatividade entre os participantes, no ambiente virtual, como discussões e trocas de experiências.

As deficiências relacionadas às ferramentas para interatividade - tanto do professor quanto do aluno - podem ser sanadas com um ambiente virtual aprimorado, que disponha de mais recursos como salas para vídeo conferências, chat e melhor funcionalidade das ferramentas do Fórum.

Apesar disto, todo programa foi realizado dentro do prazo previsto.

Percebeu-se, também, a necessidade de criar um espaço para cada aluno poder armazenar as tarefas feitas no decorrer das aulas. Estas tarefas eram enviadas, por e-mail, ao professor, o que provocou acúmulo de mensagens, dificuldades para dar.

O questionário avaliativo do programa envolveu 42 questões, sendo a maioria objetiva, referente ao ambiente virtual, a especificidades técnicas, aos materiais, às aulas, ao conteúdo, deixando espaços para comentários livres. As três últimas questões dissertativas é que serviram para avaliar o grau de satisfação e aproveitamento do aprendizado alcançados no programa.

A primeira questão solicitou a indicação de propostas de melhoria para o programa da capacitação, de maneira geral, para os quais foi possível levantar as seguintes sugestões, conforme apresenta a Tabela 3: 
Tabela 1 - Sugestões para melhorias do programa

\begin{tabular}{l|c}
\hline Sugestão & Alunos \\
\hline Ampliar carga horária & 2 \\
\hline $\begin{array}{l}\text { Continuidade do contato com integrantes do } \\
\text { curso, mesmo após encerrar }\end{array}$ & 1 \\
\hline Chat's & 2 \\
\hline Fóruns com mais ferramentas & 1 \\
\hline $\begin{array}{l}\text { Ferramentas para possibilitar maior interação } \\
\text { entre participantes }\end{array}$ & 5 \\
\hline Material didático impresso e DVD & 1 \\
\hline $\begin{array}{l}\text { Todo material deve estar dentro do ambiente } \\
\text { do curso e não em links }\end{array}$ & 1 \\
\hline Sem sugestões, tudo ótimo & 4 \\
\hline
\end{tabular}

A segunda questão solicitou a construção de uma crítica em relação ao curso, salientando aspectos positivos e negativos, para os quais foi possível levantar os seguintes enfoques, apontados na Tabela 2.

Tabela 2 - Aspectos positivos e negativos apontados pelos participantes

\begin{tabular}{|c|c|}
\hline Positivos & Negativos \\
\hline $\begin{array}{l}\text { - Iniciativa do curso. } \\
\text { - Clareza na postagem de conteúdos e } \\
\text { atividades. } \\
\text { - Atendimento às dúvidas sempre que } \\
\text { solicitado. } \\
\text { - Material escolhido para o curso. } \\
\text { - Ambiente virtual de aprendizagem. } \\
\text { - Conteúdos fornecidos. } \\
\text { - Curso muito bem elaborado a partir de } \\
\text { textos atuais e temas ricos com muitas } \\
\text { possibilidades de discussão. } \\
\text { - Material disponibilizado de fácil } \\
\text { acesso e interpretação. } \\
\text { - Atividades propostas com leituras } \\
\text { diversificadas. } \\
\text { - Forma como foram propostas e } \\
\text { desenvolvidas as atividades. } \\
\text { - O apoio da tutora. } \\
\text { - Os vídeos. } \\
\text { - Curso bem direcionado, diferente da } \\
\text { maioria dos trabalhos da área } \\
\text { ambiental, ligados à educação, o } \\
\text { material e exercícios propostos foram } \\
\text { ótimos, criativos e de boa aplicação } \\
\text { prática. } \\
\text { - Atenção e organização da tutora. }\end{array}$ & $\begin{array}{l}\text { - Carga horária (deveria ser maior). } \\
\text { - Poucas possibilidades de interação } \\
\text { entre os participantes. } \\
\text { - Pouco tempo para ler e analisar os } \\
\text { textos. } \\
\text { - Falta de retorno sobre as } \\
\text { atividades realizadas. } \\
\text { - Problemas em acessar a página do } \\
\text { curso. } \\
\text { - Fórum desorganizado - com vários } \\
\text { tópicos para responder a mesma } \\
\text { questão. } \\
\text { - Materiais em ambientes virtuais } \\
\text { externos. } \\
\text { - Prazo para a realização das } \\
\text { atividades. }\end{array}$ \\
\hline
\end{tabular}




\section{Monografias Ambientais}

REMOA

ISSN:

A terceira questão relevante do questionário aplicado solicitou que respondessem: "Dentro da sua realidade, ter feito o curso representará avanços em sua prática?" e que justificassem. Todos os participantes responderam que sim e explicaram o porquê.

Pelas respostas apresentadas foi possível perceber o quanto um programa como este pode colaborar para a melhoria da qualidade da EA em diferentes ambientes e contextos educacionais, principalmente por evidenciar maior segurança e clareza quanto a definição da EA e seus aspectos legítimos, presentes nos documentos referência.

A declaração de que o programa mudou a forma de um aluno pensar a EA indica uma grande transformação que implicará em mudança na sua prática.

Outro aluno salienta que melhorará sua argumentação, pois terá maior autoridade para inserir a EA no currículo, indicando maior segurança para lidar com a implantação da EA no currículo do seu universo de trabalho.

O reconhecimento do curso como uma grande novidade na área da educação destaca o sentido inovador da proposta.

Alguns participantes relataram perceberem avanços em suas práticas já no decorrer do curso, o que dá mais valor ainda ao programa.

\section{CONCLUSÕES}

A pesquisa bibliográfica, bem como a aplicação do programa de capacitação desenvolvido, possibilitou obter resultados valorosos para o aprimoramento da Educação Ambiental. Sem dúvida a experiência proporcionou aos professores - e a outros profissionais ligados à EA -, maior conhecimento e reflexões com os principais documentos referência, favorecendo melhorar a qualidade de sua aplicação.

A partir dos resultados dessa pesquisa exploratória e do estudo de caso é possível afirmar que o programa promove, sim, a melhoria da qualidade da prática da EA, uma vez que:

$\checkmark$ Favorece aos professores e outros profissionais ligados à EA conhecerem, de forma mais aprofundada, os documentos referência de EA que balizam essa prática educativa.

$\checkmark$ Compreende-se que os espaços educacionais onde atuam estes profissionais que participaram do programa alcançarão melhores resultados em suas práticas pedagógicas, oportunizando o alcance dos objetivos da EA, explícitos em seus documentos referência.

$\checkmark$ Os docentes e profissionais que participaram do programa estão mais seguros para desenvolver a EA de forma alinhada aos princípios e objetivos que a norteiam.

Em parte, um dos objetivos específicos não foi alcançado, conforme observado no andamento das atividades e pela avaliação final do programa, que foi o de "apresentar e trocar sugestões de ações de EA entre os participantes do curso para que possam colaborar para a superação de dificuldades encontradas", evidenciando que o ambiente virtual não favoreceu, de forma satisfatória, um espaço para troca de ideias e experiências em forma de debates.

Por fim, considera-se ter alcançado com sucesso o objetivo principal dessa proposta.

\section{REFERÊNCIAS}

ADAMS, B. G.; ADAMS, E. F. G. Educação ambiental e a água: a importância da informação como ferramenta pedagógica na educação infantil e séries iniciais. Olam: Ciência \& Tecnologia. Vol. 8, №. 3, 


\section{Monografias Ambientais}

ISSN:

2008. Disponível em: <http://cecemca.rc.unesp.br/ojs/index.php/olam/article/view/2152/2019> . Acesso em 14 mai. 2010.

BELLONI, M. L. Ensaio sobre a educação à distância no Brasil. IN: Educação \& Sociedade, ano XXIII, no 78, Abril/2002.

BOFF, L. Palestra de Leonardo Boff - Agenda 21/ Fórum Social Mundial 2005. Disponível em: <http://www.apoema.com.br/boff2.htm>. Acesso em: 8 dez. 2009.

Ecologia e espiritualidade. In: TRIGUEIRO, A. (Coord.). Meio Ambiente no século 21: 21 especialistas falam da questão ambiental nas suas áreas de conhecimento. Rio de Janeiro: Sextante, 2003.

Saber cuidar: ética do humano, compaixão pela terra. Petrópolis: Vozes. 1999.

BRASIL, Ministério da Educação e do Desporto, Lei no. 9.795 de 27 de abril de 1999. Dispõe sobre a educação ambiental, institui a Política Nacional de Educação Ambiental e dá outras providências. Diário Oficial da República Federativa do Brasil, Brasília, n. 79, 28 abr. 1999.

. Ministério da Educação e do Desporto. Secretaria de Educação Média e Tecnológica. Parâmetros

Curriculares Nacionais. Brasília, 1999.

. Ministério da Educação e do Desporto. Lei de Diretrizes e Bases da Educação Nacional,1999.

CARTA DA TERRA, 1992, Disponível em: <www.cartadaterra.com.br> Acesso em: 8 dez. 2009.

COELHO, C. C. de S. R. FIALHO, F. A. P. Espaços digitais para melhor aprendizagem, in: Diálogo Educ., Curitiba, v. 7, n. 22, p. 165-174, set./dez. 2007.

COIMBRA, J.de A. A. Considerações sobre a Interdisciplinaridade. In: Philippi Jr., Arlindo.

Interdisciplinaridade em Ciências Ambientais.C. E. M. Tucci, D. J. Hogan, R. Navegantes. - São Paulo : Signus Editora, 2000.

FORUM INTERNACIONAL DAS ONGs. Tratado de educação ambiental para sociedades sustentáveis e responsabilidade global. Rio de Janeiro: 1992.

FURTADO, D. J. Os caminhos da educação ambiental nos espaços formais de ensino-aprendizagem: qual o papel da política nacional de Educação Ambiental? Rev. eletrônica Mestrado Educação Ambiental. ISSN 1517-1256, v. 22, janeiro a julho de 2009. Disponível em:

<http://www.remea.furg.br/edicoes/vol22/art24v22.pdf> Acesso em: 20/10.09.

GASPAR, M. I. Duas metodologias de ensino em educação à distância on-line. In: Revista Discurso, Departamento de Ciências de Educação da Universidade Aberta, 2008. Acesso a Universidade Aberta em: 05/12/2009.

GOUVÊA, G. R. R. Rumos da formação de professores para a Educação Ambiental. Educar, Curitiba: Editora UFPR, n. 27, p. 163-179, 2006.

FRACALANZA, H.; et all. A educação ambiental no Brasil. Ciências em Foco. Vol. 01 - № 01, agosto 2008. Disponível em: < http://www.fe.unicamp.br/formar/revista/N000/capa000.htm> Acesso em 12/04/2010. 


\section{Monografias Ambientais}

LEFF, E. Complexidade, Interdisciplinaridade e Saber Ambiental. In: Philippi Jr., Arlindo.

Interdisciplinaridade em Ciências Ambientais.C. E. M. Tucci, D. J. Hogan, R. Navegantes. - São Paulo : Signus Editora, 2000.

MEDINA, N. M. A formação dos professores em educação ambiental. In: Panorama da educação ambiental no ensino fundamental / Secretaria de Educação Fundamental - Brasília : MEC ; SEF, 2001.

PARÂMETROS CURRICULARES NACIONAIS: meio ambiente:saúde / Secretaria de Educação Fundamental. 2. ed. - Rio de Janeiro: DP\&A, 2000.

PENTEADO. H. D. Meio ambiente e formação de professores. São Paulo: CORTEZ EDITORA, 1997.

PRODANOV, C. C.; FREITAS, E. C. de. Metodologia do trabalho científico: método e técnicas da pesquisa e do trabalho acadêmico. Novo Hamburgo: Feevale, 2009.

QUINTAS, J. S. Educação no processo de gestão ambiental: uma proposta de educação ambiental transformadora e emancipatória. In: LAYRARGUES, P. P. (Coord.). Identidades da educação ambiental brasileira / Ministério do Meio Ambiente. Diretoria de Educação Ambiental; - Brasília: Ministério do Meio Ambiente, 2004.

SANTOS, J. F. S. Avaliação no Ensino a Distância. In: Revista Iberoamericana de Educación (ISSN: 16815653), 2006, s/v, s/p. Disponível em: <http://www.rieoei.org/.> Acesso: em: 05.12 .09

TRAJBER R.; MENDONÇA P. R. (Org.s) Educação na diversidade: o que fazem as escolas que dizem que fazem educação ambiental. Brasília: Secretaria de Educação Continuada, Alfabetização e Diversidade, 2006.

UNIVERSIDADE FEDERAL DE SANTA MARIA. Pró-Reitoria de Pós-Graduação e Pesquisa. Estrutura e apresentação de monografias, dissertações e teses : MDT. 6.ed. Santa Maria, 2006.

VEIGA, Alinne et all. Um Retrato da Presença da Educação Ambiental no Ensino Fundamental Brasileiro: o percurso de um processo acelerado de expansão. Brasília: Instituto Nacional de Estudos e Pesquisas Educacionais Anísio Teixeira, 2005.

VERGARA, Sylvia Constant. Projetos e relatórios de pesquisa em administração. São Paulo: Editora ATLAS, 2000.

VIEZZER, M.; OVALLES, O. (Orgs.) Manual latino-americado de educ-ação ambiental. São Paulo: Gaia, 1994.

ZANONI, M. Práticas Interdisciplinares em Grupos Consolidados. In: Philippi Jr., Arlindo.

Interdisciplinaridade em Ciências Ambientais.C. E. M. Tucci, D. J. Hogan, R. Navegantes. - São Paulo : Signus Editora, 2000. 